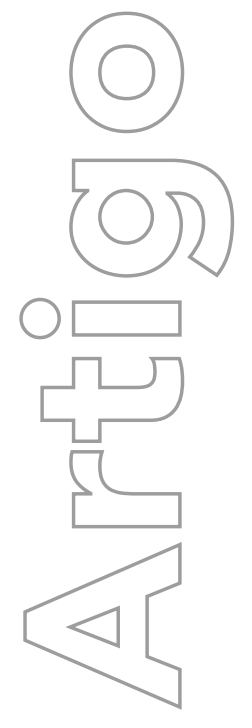

revista

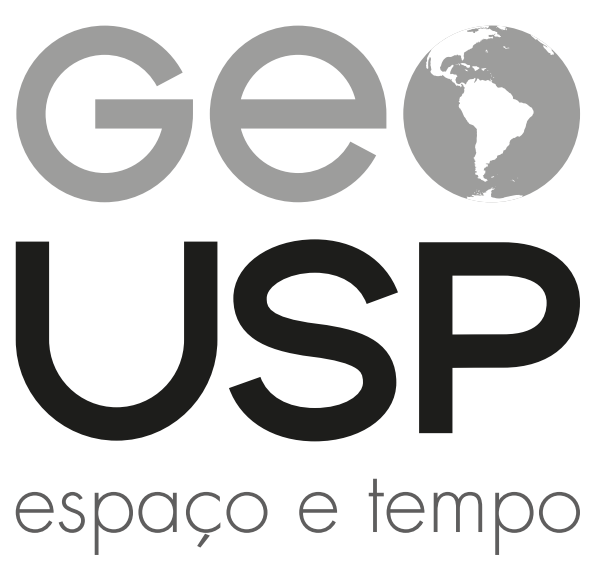

Volume $25 \cdot n^{\circ} 1(2021)$

ISSN 2179-0892

\section{Metodologia para} classificação de hidrossítios: rio Selho, no Concelho de Guimarães, distrito de Braga, Portugal

\author{
Eliane Maria Foleto ${ }^{\mathrm{a}}$ \\ a Universidade Federal de Santa Maria. \\ Santa Maria. Rio Grande do Sul. Brasil \\ efoleto@gmail.com \\ (1) 0000-0003-2205-7801 \\ Francisco Silva Costab \\ b Universidade Federal de Santa Maria. \\ Santa Maria. Rio Grande do Sul. Brasil \\ costafs@geografia.uminho.pt \\ (1) 0000-0001-7041-7811
} e-172586

Como citar este artigo:

FOLETO, E. M.; COSTA, F. S. Metodologia para classificação de hidrossítios: rio Selho, no Concelho de Guimarães, distrito de Braga, Portugal. Geousp, v. 25, n. 1, p. 1-24, e-172586, 2021. ISSN 2179-0892.

Disponível em: https://www.revistas.usp.br/geousp/article/ view/172586. doi: https://doi.org/10.11606/issn.2179-0892. geousp.2021.172586.

\section{(c) $\underset{\mathrm{By}}{\mathrm{By}}$}

Este artigo está licenciado sob a Creative Commons Attribution 4.0 Licence 


\title{
Metodologia para classificação de hidrossítios: rio Selho, no Concelho de Guimarães, distrito de Braga, Portugal ${ }^{1}$
}

\section{Resumo}

Com o objetivo de criar uma metodologia especifica para classificação de hidrossítios, propõe-se que, na avaliação dos locais interesse hidrológico $(\mathrm{LIH})$, o valor patrimonial seja definido pelos critérios ecológico, estético, sociocultural e complementar, seus respectivos indicadores e classes. Para facilitar o mecanismo da avaliação, criou-se a Ficha de Levantamento Hidrológico, validada em dois LIH do rio Selho no Concelho de Guimarães, Distrito de Braga, Portugal. Como resultado, a proposta para a classificação de hidrossítios demonstra coerência teórico-metodológica com a condição hídrica verificada em campo, o que valida os critérios, indicadores, classes com os respectivos índices percentuais. Após a ponderação dos valores atribuídos às classes, a metodologia demonstra que os $\mathrm{LIH}$ do rio Selho não têm valoração suficiente para ser considerados hidrossítios, por apresentarem alguns problemas ambientais; mas, embora não tenham atrativos monumentais, merecem medidas de proteção e o reconhecimento de seu valor hídrico.

Palavras-chave: Geopatrimônio. Locais de interesse hidrológico. Valor ecológico. Querem dar mais duas palavras-chave?

\section{Methodology for the classification of hydrosites: Selho River in Guimarães Council, District of Braga, Portugal}

\begin{abstract}
Aiming to elaborate a specific methodology for the classification of Hydrosites, we propose that in the evaluation of the Sites of Hydrological Interest (SHI) the patrimonial value is defined by the criteria: ecological, aesthetic, sociocultural and
\end{abstract}

Este trabalho foi realizado com apoio da Coordenação de Aperfeiçoamento de Pessoal de Nível Superior - Brasil (Capes) - Código de Financiamento 001. Estágio de pós-doutorando, Centro de Estudos da Comunicação e Sociedade (Cecs), Programa de Pós-Graduação em Geografia, Universidade do Minho campus Azurém, Guimarães, Portugal. 
complementary, and their respective indicators and classes. In order to facilitate the evaluation mechanism we elaborated a Hydrological Survey Sheet, validated in two SHI of Selho River in Guimarães Council, District of Braga, Portugal. As a result, the Proposal for the Classification of Hydrosites demonstrates theoreticalmethodological coherence with the hydric condition verified in the field, which validates the criteria, indicators, classes with the respective percentage indexes. After weighting of the values attributed to the classes, the methodology demonstrates that the SHI of Selho River do not have enough valuation to be considered Hydrosites because they present some environmental problems, the potentialities even not having monumental attractions are worthy of protective measures and of recognition of their hydric value.

Keywords: Geoheritage. Sites of hydrological interest. Ecological value.

\section{Metodología para clasificación de hidrositas: Río Selho en el Consejo de Guimarães, Distrito de Braga, Portugal}

\section{Resumen}

Con objetivo de elaborar una metodología específica para clasificación de Hidrositas se propone que en la evaluación de los locales interés hidrológico ( $\mathrm{LIH}$ ) el valor patrimonial sea definido por los criterios: ecológico, estético, sociocultural y complementar, sus respectivos indicadores y clases. Para facilitar el mecanismo de la evaluación se elaboró la Ficha de Levantamiento Hidrológico, validada en dos LIH del Río Selho en el Consejo de Guimarães, Distrito de Braga, Portugal. Como resultado la Propuesta para la Clasificación de Hidrositas demuestra coherencia teórico metodológica con la condición hídrica verificada en campo, lo que valida los criterios, indicadores, clases con respectivos índices porcentuales. Después de la ponderación de los valores atribuidos a las clases, la metodología demuestra que los LIH del Río Selho no poseen valoración suficiente para que sean considerados Hidrositas por presentar algunos problemas ambientales, las potencialidades aunque no posean atractivos monumentales son merecedores de medidas de protección y del reconocimiento de su valor hídrico.

Palabras clave: Geopatrimonio. Locales de interés hidrológico. Valor ecológico. 


\section{Introdução}

A água sempre esteve próxima à sociedade, influenciando a cultura e sendo transformada. $\bigcirc$ atual contexto, porém, demanda um novo olhar, com o intuito de ressignificar a conservação de um bem de uso comum, vital para a sobrevivência dos seres vivos na Terra. Olhar a água como elemento de valor patrimonial é ler a água em todas as suas dimensões, do ecológico ao social, admitir também a ideia de olhar para as margens a partir da água, numa abordagem histórica, conforme Peyret (2016), considerando os rios como vias de conexão, de acesso que testemunharam o processo de ocupação e desenvolvimento das sociedades.

Para a valoração dos corpos hídricos, na perspectiva do geopatrimônio, o elemento hidrológico precisa ser reconhecido como os demais elementos da geodiversidade: geológico e geomorfológico. Constata-se, no entanto, que ele ainda demanda metodologia específica, sendo estudado como sinônimo de patrimônio hidráulico ou indiretamente na abordagem do patrimônio geológico e geomorfológico.

Pela sua importância, há necessidade de estudos e pesquisas que contemplem as características específicas do corpo hídrico:

balanço dos últimos 20 anos de pesquisa sobre património geomorfológico é muito satisfatório. De uma situação mais ou menos generalizada de inclusão do património geomorfológico no património geológico, passou-se a uma clara autonomia e afirmação da importância dos geossítios de caráter geomorfológico (geomorfossítios) que representam a maior parte dos geossítos da Terra. De facto, de fora apenas ficam os de caráter geológico (estruturas, séries sedimentares e referências estratigráficas e paleogeográficas ou paleontológicas), os ligados ao património pedológico (pedossítios) e os relacionados com o património hidrológico, bastante negligenciados, como as águas oceânicas e continentais (mares, lagos, cursos de água, reservatórios subterrâneos e hidro-termais) bem como a dinâmica, processos e formas associados (Rodrigues, 2019, p. 78).

Além disso, em relação ao património hidrológico, Simić, Gavrilović e Belij (2010) e Rodrigues (2019) reforçam a necessidade de maior investigação de conceitos e da aplicação, embora os fenômenos hidrológicos estivessem de alguma forma presentes no geopatrimônio, eles necessitam de estudos específicos separados dos demais elementos da geodiversidade.

Considerando que os elementos da geodiversidade podem ser usados para impulsionar a conservação e o desenvolvimento das comunidades locais por meio de atividades de interação com o patrimônio e sendo a água um recurso indispensável para a humanidade, pois mantém a vida do planeta Terra e suporta todos os ciclos naturais (Tundisi; MatsumuraTundisi, 2020, p. 15), essa deve receber a devida importância, com a indicação de local de interesse hidrológico $(\mathrm{LIH})$, ressignificando a importância e a necessidade urgente da conservação frente ao poder público e a coletividade.

Para contribuir com a discussão sobre o elemento hidrológico, o artigo visa apresentar uma metodologia para avaliação e classificação de hidrossítios para compor o patrimônio hidrológico de determinado território, ressignificando a importância da conservação pela valoração da água. 
processo para a avaliação e classificação de hidrossítios com critérios, indicadores e classes demanda levantamentos com dados de campo, apontando aspectos positivos e negativos do corpo hídrico, "Contribuindo desta forma para o Gerenciamento de Recursos Hídricos onde o conhecimento dos sistemas hidrológicos é essencial para uma gestão eficaz dos recursos hídricos" (Oliveira; Pessoa; Steinke, 2019, p. 29).

\section{Metodologia}

Partindo da necessidade de elaborar uma metodologia que contemple as especificidades do elemento hidrológico e não se afaste ou sobreponha à abordagem dos demais elementos da geodiversidade, algumas questões foram elencadas. Quais critérios, indicadores e classes, entre os apresentados para o geopatrimônio e o patrimônio hidráulico, poderiam ser adotados para o elemento hidrológico? Que características deve ter o corpo hídrico para ser definido como um $\mathrm{LIH}$ ? Que critérios, indicadores e classes dariam conta de avaliar os $\mathrm{LIH}$ para defini-los e classificá-los como hidrossítios.

Para subsidiar essas questões, inicialmente, foi realizado um levantamento sistemático de artigos científicos das bases de dados Capes, Scielo, Scopus, Clarivate e RCAAP. Com a busca, foi possível identificar os trabalhos, autores, abordagens e metodologias utilizadas para a definição de: patrimônio hídrico, hidrológico, hidráulico e hidrossítios.

Para a elaboração da proposta de avaliação e classificação de hidrossítios, usaram-se o levantamento teórico e metodológico da geoconservação e dos fundamentos da hidrologia (Esteves, 1998; Tucci, 2010), o estudo do patrimônio hidrológico da Sérvia (Simić; Gavrilović; Belij, 2010) e as análises de corpos hídricos realizadas em trabalhos de campo no primeiro semestre de 2020.

No estudo dos elementos da geodiversidade, Brilha (2005) propõe um conjunto de procedimentos para chegar a definição do geopatrimônio. Sendo que, para Rodrigues e Fonseca (2008), o geopatrimônio contempla elementos geológicos, geomorfológicos, hidrológicos e pedológicos, entre outros, e os componentes da geodiversidade se complementam no valor da pesquisa científica, da educação, da estética e da cultura. E o patrimônio geomorfológico constituído pelas formas do relevo, depósitos correlativos e processos associados, manifestados a diferentes escalas e aos quais se atribui um conjunto de valores (científico-pedagógico, estético, cultural, ecológico e/ou econômico) decorrentes da percepção humana, conforme definem Vieira, Figueiró e Cunha (2014).

Seguindo o pressuposto de que os elementos da geodiversidade devem apresentar valor científico, estético e cultural, definem-se critérios, indicadores e classes baseados nas metodologias propostas por Simić, Gavrilović e Belij (2010), Simić, Milovanović e Jojić Glavonjić (2014), Vieira, Figueiró e Cunha (2014), Pereira, Cunha e Theodoro (2016) e Oliveira, Pessoa e Steinke (2019) e pelo River Habitat Survey (RHS), que atende à Diretiva do Quadro da Água (DQA) (Parlamento Europeu, 2000), e também por Pio e Henriques (2000), Medeiros (2011), Monteiro (2013), Ramos-Merchante e Prenda (2015) e pelo Ministério do Ambiente do Ordenamento do Território e do Desenvolvimento Regional (Portugal, 2009). Dessas metodologias, foram analisados e ponderados indicadores para atender às especificidades hídricas que permitem, entre os $\mathrm{LIH}$, classificar os que apresentam condição para hidrossítio. 
Como resultado, a avaliação de corpos hídricos evidencia: a qualidade da água, a dinâmica da corrente - lênticos (lagos) e lóticos (rios, e riachos) e as intervenções para uso da água. Considera que a água esteve próxima às comunidades e contribuiu para o mosaico de uso e ocupação da terra (Peyret, 2016), nesse sentido, os critérios ecológicos, estéticos, socioculturais e complementar do arranjo com os demais elementos da geodiversidade foram contemplados na proposta para serem valorados.

Assim, o LIH deve ter características excepcionais de qualidade da água, dinâmica hídrica e intervenções para uso dos recursos hídricos, em que o estado ecológico da qualidade e da condição hidromorfológica do corpo hídrico define o critério essencial.

A proposta de avaliação hidrológica constitui um sistema quali-quantitativo baseado nas características relevantes do elemento hidrológico não se sobrepondo aos demais elementos da geodiversidade. Independentemente da sua aplicação, este índice deve ser utilizado apenas para classificar e comparar corpos hídricos, a sua calibração, a partir da classificação obtida nos locais considerados com melhor qualidade hídrica, estabelecendo assim a referência para uma avaliação comparativa. A pontuação serve de referência para quantificar critérios, indicadores e classes com enfoque na avaliação de corpos hídricos excepcionais sendo resultado do conhecimento empírico, das diferentes metodologias do geopatrimônio e do RHS, sendo necessário ainda qualificá-la, testá-la e eventualmente adaptá-la a outras regiões e países.

Após a elaboração da proposta metodológica com a definição dos critérios, indicadores e classes, foi montado um procedimento de avaliação sistematizado na Ficha de Levantamento Hidrológico para obter dados em campo. Outra etapa do trabalho foi a validação da proposta em LIH no rio Selho, Concelho de Guimarães, Distrito de Braga situado a noroeste de Portugal.

Com os procedimentos de avaliação e validação da proposta metodológica concluídos, o resultado deve demonstrar se os $\mathrm{LIH}$ selecionados têm valor patrimonial, para, assim, ser usada na classificação de hidrossítios em Portugal e no Brasil.

\section{Resultados}

\section{Considerações sobre o levantamento hidrológico}

Para inventariação, valoração e classificação, considera-se hidrossítio um corpo hídrico raro, excepcional, quanto à qualidade da água, características hidromorfológicas, qualidade visual do canal, do entorno e, das intervenções para o uso da água, com importância: científica, de gestão e da geomorfologia fluvial em um território. Sendo que, para Simić, Gavrilović e Belij (2010, p. 87, tradução nossa), o patrimônio hidrológico é um segmento da diversidade hidrológica que se destaca pela abundância de fenômenos e objetos aquáticos com valores ambientais, científicos, educacionais, sociocultural e senso estético.

Os locais de interesse especial ou sítios (geossítios, geomorfossítios, pedossítios e hidrossítios) são porções pontuais do geopatrimônio cujos valores potencializam-se, de acordo com Pereira, Cunha e Vieira (2016). Além disso:

Os locais de interesse patrimonial no domínio da água, que são representativos pela sua condição de exclusividade e representatividade, importância científica, por 
exemplo como definidor (paleo)ambiental, de suporte ecológico, de valor estético, entre outros (Pereira; Cunha; Theodoro, 2016, p. 296).

Para a classificação de hidrossítios, um dos procedimentos iniciais é a realização do inventário dos corpos hídricos, etapa da coleta de dados que dá suporte para as demais. Entre as variáveis do meio físico relativas à água, consideram-se dois aspectos - disponibilidade e qualidade -, e as formas de ocorrência da água podem-se estruturar inicialmente em superficial e subterrânea (Aguilo Alonso et al., 2004, p. 53), com a definição de uma escala para a abordagem dos processos morfodinâmicos e dos fatores de controle que regem o sistema fluvial, bem como da escala temporal em que eles se processam (Monteiro, 2013; Stevaux; Latrubesse, 2017).

Os critérios para a valoração hidrológica de acordo com sua importância são: o ecológico e educacional, o estético e, finalmente, o critério sociocultural (Simić; Milovanović; Jojić Glavonjić, 2014). Na definição dos indicadores hidrológicos, considera-se que o espaço torna-se testemunho das vivências humanas, um elemento significante da sua história, como um lugar de inscrição do passado, das práticas, dos hábitos ligados aos seres vivos (Peyret, 2016), e, entre os valores patrimoniais hidráulicos, os culturais, ambientais, paisagísticos e socioeconômicos são elencados por Hervás e Serrano (2012). Ademais, entre as metodologias aplicadas aos elementos da geodiversidade, considera-se que:

A escolha dos critérios para a avaliação é o ponto crucial da pesquisa e a maioria dos critérios propostos por diferentes pesquisadores revelam um consenso nas características a serem valorizadas, ou seja, o valor científico/didático/educativo, o valor ecológico, o valor cultural, o valor estético, o valor econômico e o valor funcional (Oliveira; Pessoa; Steinke, 2019, p. 33).

Em relação ao exposto, a proposta considera que, na avaliação dos LIH, os critérios, indicadores e classes deverão contemplar a excepcionalidade, a avaliação positiva atribuirá o status de hidrossítio ao corpo hídrico, que não necessariamente seja monumental ou aqueles para os quais o mercado turístico vê grande possibilidade de exploração, mas outro entendimento, que leva em conta as características naturais, a relação com a história dos grupos, com o lugar e as práticas socioespaciais (Scifoni, 2006).

\section{Proposta metodológica para a valoração do corpo hídrico}

A construção da proposta metodológica para avaliação e classificação de hidrossítios baseou-se nos modelos usados para os elementos da geodiversidade (geológica, geomorfológica e hidrológica), considerando o proposto por Brilha (2005); os critérios para classificação de elementos geomorfológicos conforme Vieira, Figueiró e Cunha (2014) e o modelo de identificação e avaliação de sítios para o patrimônio hidrológico de acordo com Simić, Milovanović e Glavonjić (2014) e Oliveira, Pessoa e Steinke (2019).

Tomando como base o trabalho dos autores citados e o RHS, DQA (Parlamento Europeu, 2000), que estabelece um sistema integrado de medidas à proteção das águas (Pio; Henriques, 2000, p. 4; Medeiros, 2011, p. 18), propõe-se, na avaliação hidrológica (Quadro 1), 
uma sequência em que o principal critério a ser considerado seja o de valor ecológico (essencial), por contemplar a especificidade hídrica da qualidade e dinâmica da água, indispensáveis para atribuir valor patrimonial. Complementando com critérios de valoração (universal): estético e sociocultural, também propostos para a avaliação de geomorfossítios, acrescido de valor (complementar) que demonstra a importância: científica pelos importância para estudos; pelas Políticas de gestão e; ainda da geomorfologia fluvial, na sequência, são apresentados os critérios, indicadores classes propostos para a avaliação e classificação de hidrossítios

\section{Quadro 1 - Critérios e indicadores com os respectivos índices percentuais para avaliação do LIH}

\begin{tabular}{|c|c|}
\hline Critério ecológico (65\%) & Indicadores \\
\hline \multirow{4}{*}{ Qualidade da água (40\%) } & $\mathrm{pH}, \mathrm{OD}$, condutividade (12\%) \\
\hline & Estado trófico da água (10\%) \\
\hline & Biodiversidade aquática (10\%) \\
\hline & Condição margens (8\%) \\
\hline \multirow{4}{*}{ Características hidromorfológicas (25\%) } & Tipologia $(2,5 \%)$ \\
\hline & Transponibilidade $(7,5 \%)$ \\
\hline & Balanço erosão/deposição $(7,5 \%)$ \\
\hline & Forma (dinâmica) $(7,5 \%)$ \\
\hline Critério estético (10\%) & Indicadores \\
\hline \multirow{2}{*}{ Qualidade visual (10\%) } & Leito (5\%) \\
\hline & Cobertura da terra (5\%) \\
\hline Critério sociocultural (15\%) & Indicadores \\
\hline \multirow{2}{*}{ Bens e equipamentos (15\%) } & Significado histórico $(7,5 \%)$ \\
\hline & Função de uso água $(7,5)$ \\
\hline Critério complementar (10\%) & Indicador \\
\hline Científico $(2,5 \%)$ & Importância científica $(2,5 \%)$ \\
\hline Gestão (5\%) & Políticas de gestão (5\%) \\
\hline Geológico/geomorfológico 2,5\%) & Estrutura/processos $(2,5 \%)$ \\
\hline Valor $100 \%$ & Valor $100 \%$ \\
\hline
\end{tabular}

organização: Os autores, 2020.

A escolha dos critérios e indicadores específicos para a água baseia-se na DQA (Parlamento Europeu, 2000), com o conceito estado ecológico da água, e considera as massas de água um ecossistema, que é avaliado por meio de indicadores físico-químicos, hidromorfológicos e biológicos (Pio; Henriques, 2000; Monteiro, 2013; Ramos-Merchante; Prenda, 2015), que permitem compreender melhor o impacto da influência antrópica na dinâmica morfológica dos sistemas hidrológicos.

A hidromorfologia representa o habitat físico do rio, resultante da morfologia do canal e tipos de fluxo de água, resultado do regime hidrológico do sistema fluvial, do tipo e proporção relativa de substratos geológicos do leito, e dos padrões de erosão e sedimentação de materiais que a eles estão associados (Ferreira; Aguiar, 2006, p. 420). 
A DQA alicerçou legalmente essa nova visão de qualidade dos ecossistemas, alterando a gestão dos recursos hídricos nos Estados-membros (Pio; Henriques, 2000; Monteiro, 2013). A partir desta, a gestão dos recursos hídricos passa a atender, além das necessidade dos usos humanos, a necessidade dos ecossistemas, trazendo uma abordagem com valores de motivação ética de preservação e respeito à vida.

A avaliação ecológica das águas expressa a qualidade estrutural e funcional do ecossistema aquático associado as águas de superfície, tanto dos fatores naturais fisiográficos, geográficos e climáticos como as condições físicas e químicas, incluindo as que resultam de atividades humanas, conforme Pio e Henriques (2000), em que consideram:

Qualidade adequada o corpo hídrico deve ser tratado como o resultado do conjunto de inter-relações entre seus componentes com condições de integridade, capacidade de suportar e manter as comunidades de organismos equilibrada, integrada e adaptada, com funcionalidade comparável ao habitat natural da região proporcionando qualidade de vida (Ramos-Merchante; Prenda, 2015, p. 212).

Nesse sentido, a água deve manter a capacidade de sustentar ecologicamente o recurso hídrico (Selborne, 2001), em outras palavras, o ambiente natural passa a ser entendido como usuário, que, por sua vez, deve ter acesso a ele para poder se manter (e ao próprio ambiente hídrico) em equilibrio.

Baseado no exposto, um hidrossítio deve ter valor ecológico, avaliado por meio de indicadores: qualidade da água (acidez/PH, oxigênio dissolvido/OD, condutividade, biodiversidade aquática, estado trófico e cobertura das margens) e condição hidromorfológica (tipologia, transponibilidade, balanço erosão/deposição e forma/dinâmica).

Com base nesses critérios, definiram-se as classes, com valores de 0 a 4, considerando esta a melhor condição hídrica e aquela, a pior. A definição das classes foi obtida do Projeto Inventariação e Avaliação Ambiental de Obstáculos no Rio Selho para Decisão de Remoção e Valorização da Linha de Água e posteriormente validada em levantamento de trabalho de campo no rio Selho, com possibilidade de avaliação de diferentes situações hídricas, ambientais e de uso e cobertura da terra.

O critério ecológico permite avaliar a qualidade e o estado de conservação dos habitats fluviais, a partir da sua hidromorfologia e estrutura da vegetação ribeirinha e aquática (Portugal, 2009). Em consonância com o RHS (Medeiros, 2011), os principais indicadores a ser avaliados por classes para definir a qualidade da água são:

(a) o potencial hidrogeniônico $(\mathrm{pH})$, que especifica a acidez ou basicidade de uma solução aquosa. $\bigcirc \mathrm{pH}$ contribui para definir o grau de solubilidade de relevância na determinação da qualidade da água, abrangendo a faixa de 0 a 14 (inferior a 7: condições ácidas; superior a 7: condições alcalinas) (Brasil, 2014), sendo definidas as seguintes classes: excelente: 6,5-8,5; bom: 5,5-9; razoável: 5-10; ruim: 4.5-1 e muito ruim: > 11; 
(b) o oxigênio dissolvido (OD), que define a concentração de oxigênio $\left(\mathrm{O}^{2}\right)$ contido na água, essencial para todas as formas de vida aquática. A determinação da concentração de OD é fundamental na avaliação da qualidade das águas e está envolvida em praticamente todos os processos químicos e biológicos. A descarga em excesso de material orgânico na água pode resultar no esgotamento de oxigênio do sistema e levar à morte a maioria dos organismos (Esteves, 1998). As classes percentuais são: excelente: $>90$, bom: 70-90, razoável: 50-70, ruim 30-50 e muito ruim: $<30$.

(c) a condutividade $(\mu \mathrm{S} / \mathrm{cm}, 20 \circ \mathrm{C})$, capacidade da água de conduzir corrente elétrica. Esse parâmetro é relativo à presença de íons dissolvidos na água, que são partículas eletricamente carregadas: quanto maior for a quantidade de íons dissolvidos, maior será a condutividade elétrica na água (Brasil, 2014). Excelente: $<750$, bom: 750-1.000, razoável: 1.000-1.500, ruim: 1.500-3.000 e muito ruim: $>3.000$.

Propõe-se que, na avaliação da qualidade da água dos LIH no Brasil seja tomada como referência a Resolução n. 357/2005, do Conselho Nacional do Meio Ambiente, que define cinco classes para a água doce, de especial a classe IV. A classe da qualidade refere-se ao conjunto de condições e padrões de qualidade de água necessários ao atendimento dos usos preponderantes, atuais ou futuros, e à proteção das comunidades aquáticas. No Art. 4०, as águas doces classificadas como classe especial se destinam (a) ao abastecimento humano, com desinfecção, (b) à preservação do equilibrio natural das comunidades aquáticas e (c) à preservação dos ambientes aquáticos em unidades de conservação de proteção integral (Brasil, 2005).

Quando não houver possibilidade de analisar a qualidade da água em laboratório, recomenda-se tomar como referência dados de locais próximos e a montante do ponto de análise, ou a avaliação pela análise visual interpretada por cor, cheiro, transparência.

Os valores das classes da biodiversidade aquática, estado trófico e cobertura das margens são atribuídos em acordo com as características geográficas da região, remetem à capacidade de autodepuração do corpo hídrico, se inter-relacionam e complementam com os indicadores da qualidade e da condição hidromorfológica: tipologia, transponibilidade, balanço entre erosão/deposição e forma (dinâmica), permite, pela avaliação, detectar impactos antrópicos, entre outros, modificações no regime de fluxo, do balanço da erosão/deposição de sedimentos (Pio; Henriques, 2000) contribuindo para definir o grau de conservação do canal e do corpo hídrico. O balanço de erosão/ deposição é usado na perspectiva comparativa ao estado de equilibrio natural, no qual não há modificações significativas nos fluxos de matéria e energia do sistema. Esse tipo de comparação deve levar em conta a escala do sistema/objeto analisado e a escala das alterações humanas (condição de margens e entorno) que podem interferir no rio. A forma gerada pela dinâmica fluvial pode se materializar em quedas d'água, cachoeiras e cascatas, sendo avaliadas pelo tamanho das queda e pela quantidade da vazão, como cenário dominante, expressiva e sem expressão.

$\bigcirc$ estado trófico de um corpo hídrico, associado à atividade biológica, ocorre como resultado pelo acúmulo de nutrientes como fósforo, nitrogênio, carbono e outros, que, em excesso na água, levam à proliferação exagerada da flora aquática em diferentes níveis de eutrofização 
(Esteves, 1998). $\bigcirc$ índice do estado trófico baseado nas seguintes classes: oligotrófico $<44$, mesotrófico 44-54, eutrófico 54-74 e hipereutrófico > 74.

A condição de margens consideradas zonas de transição, com características únicas, proporciona importantes serviços ecossistêmicos, desde a filtragem de nutrientes até a proteção contra cheias, sendo que o tipo de cobertura de uso da terra de margens dos cursos d'água Monteiro (2013), o regime hidrológico, a continuidade fluvial e as condições morfológicas determinam os indicativos das classes para a valoração hidromorfológica (Portugal, 2009).

Parte-se do pressuposto de que o valor patrimonial de um LIH está invariavelmente na qualidade da água e na condição hidromorfológica do corpo hídrico e, portanto, atribui-se 65\% do valor total da avaliação, sendo que os indicadores da qualidade da água recebem $40 \%$ e os hidromorfológicos $25 \%$ do valor total. $\bigcirc$ maior valor ecológico ampara-se no arcabouço metodológico do valor patrimonial, a qualidade deverá ser especial, esse percentual, valoriza em específico elemento hídrico.

Se o critério ecológico, que contempla integridade, biodiversidade e sustentabilidade, obtiver valor elevado, outros critérios devem ser considerados: o estético como universal, em que a qualidade visual do corpo hídrico se materializa pela expressão de seus componentes, na forma como se organizam e distribuem, muitas vezes, constituindo notável beleza, que atraem pelo "poder de fascinação", sentimento de admiração e bem-estar. $\bigcirc$ valor estético é resultado da combinação dos componentes da paisagem como: forma, linha, cor, textura e escala, que se organizam na formação da cena para o processamento cognitivo da avaliação, conforme Mendes (2010).

Desse modo, o critério estético do corpo hídrico estaria associado às condições de conservação, que seriam avaliados pela qualidade visual: das condições do leito e da cobertura da terra no entorno. As classes remetem à configuração harmoniosa dos canais desde a manutenção da característica natural, alterado e, totalmente alterado retificado, canalizado e, das condições do uso das margens, se o arranjo responde a uma estética diversificada, harmoniosa, de unidade e contraste (Mendes, 2010), valorosa ou não. Onde se considera que:

O canal é a estrutura que um rio constrói para otimizar a energia utilizada para o escoamento da água e dos sedimentos transportados. Suas dimensões quanto a geometria da seção (largura e profundidade), padrão (arranjo areal dos canais) e perfil longitudinal (pendente) dependem não apenas das características do fluxo (magnetude, velocidade e regime), mas também do substrato (rochoso ou aluvial) e da natureza (carga de fundo, suspensa e dissolvida) e da quantidade de material por ele transportados (Stevaux; Latrubesse, 2017, p. 155).

O critério estético contempla 10\% da avaliação total, sendo 5\% para o canal e 5\% para a cobertura da terra no entorno.

O critério sociocultural contemplado no processo de avaliação considera que a água, pela morfogênese e funcionalidade, tem protagonismo, e a ação humana intervém para ordenar e aproveitar os recursos hídricos moldando a paisagem cultural (Mata Olmo; Fernández Muñoz, 2010) e esteve próxima, influindo no mosaico de uso e ocupação do território e, assim, permanece na memória dos grupos sociais o vínculo com a natureza transformada pela ação 
cultural (Scifoni, 2006). Para Avilés e Romero (2012), as "paisagens da água” são o resultado da combinação de corpos hídricos, elementos físicos e intervenções humanas.

Nesse sentido, as intervenções e o uso dos recursos hídricos são avaliados como bens e equipamentos que se materializaram ao longo do tempo e no espaço e que determinam cenários muitas vezes raros, em virtude de seu significado histórico-cultural. Assim sendo, considera-se, na avaliação, se há função ecológica e social como um bem de uso comum ou econômico que merece ser conservado para as futuras gerações.

As classes indicam o valor dos bens e equipamentos pelo significado histórico-cultural (grande, média ou nenhuma relevância), grau de pertencimento, ou importância para a comunidade, se podem ser usados como documento histórico ou registro cultural (Cecchin, 2019) e ainda pela função do uso da água (ecológica, social ou econômica), contemplando a manutenção ecológica, o abastecimento humano e os usos múltiplos: geração de energia, recreação, lazer e esportes. Propõe-se que nesse critério haja valoração dos equipamentos e intervenções antrópicas que testemunham a história do uso da água e os de uso atual do corpo hídrico e 15\% do valor total, com 7,5\% para o significado histórico-cultural e 7,5\% para a função.

O critério complementar compõe com os demais o quarto critério para avaliação e classificação dos hidrossítios, com indicadores que complementam a importância científica dos corpos hídricos, sejam nascentes, rios ou lagos que têm, na água e/ou em fenômenos hídricos, interesse para a comunidade científica, por ser relevantes e/ou raros para a investigação. Os fenômenos hidrológicos são de grande interesse educacional, pois suas mudanças ocorrem anualmente, e, portanto as pessoas podem facilmente perceber a dinamicidade do ambiente, de acordo com Oliveira, Pessoa e Steinke (2019, p. 30), muitas vezes sendo o único exemplar na região para coleta de dados e aulas em campo. Na avaliação da gestão, as classes consideram as normas e leis de incentivo à conservação, demonstrando o reconhecimento do poder público e da sociedade na conservação ambiental e/ou da água e/ou na área de captação.

Ademais, não menos importante é o indicador geológico/geomorfológico, que avalia a representatividade dos processos fluviais e das morfologias derivadas que compõem o LIH, para o qual o rio fornece os fundamentos para sua compreensão em várias dimensões espaciais e temporais (Stevaux; Latrubesse, 2017). Assim, os processos e formas contemplados pelo estudo dos geossítios e geomorfossítios fortalecem as estratégias da geoconservação, sendo mais um elemento a contribuir com o valor hídrico. $\bigcirc$ critério complementar recebe 10\% do total da avaliação, sendo, 2,5\% para a importância científica, 5\% para a gestão e 2,5\% para a composição geológica/geomorfológica.

Propõe-se que, após a definição do LIH com potencial patrimonial, segundo os critérios: ecológico, estético, sociocultural e complementar, o próximo procedimento seja a coleta dos dados em campo para a avaliação do corpo hídrico.

Os valores atribuídos pelos índices percentuais das cinco classes no intervalo de 0 a 4 , sendo zero atribui-se para a pior condição e quatro para a melhor condição, considerando que o valor patrimonial deve ser atribuído a corpo hídrico raro e excepcional quanto a qualidade da água, dinâmica da corrente ou nas intervenções para apropriação/uso do recurso hídrico.

A proposta dos critérios, indicadores e classes foi embasada nas metodologias do geopatrimônio, do RHS, DQA (Parlamento Europeu, 2000) e do conhecimento empírico acumulado por 
pesquisadores no tema da geoconservação. Fizeram-se três expedições de campo para propor e validar a avaliação dos LIH entre os meses de maio e julho de 2020. No primeiro levantamento de campo, foram visitados cinco transectos de rios, quatro no rio Selho e um no rio Ave, com condições hídricas, estéticas, socioculturais, geomorfológicas diferenciadas pela conservação e de cobertura e uso da terra, mostrando-se adequadas ao levantamento de possíveis indicadores de avaliação hidrológica. No segundo trabalho de campo, foram visitados dois segmentos no rio Selho, previamente analisados e com potencial para ser classificados como hidrossítios; nesse momento, foram ajustados e definidos os critérios, indicadores e classes sistematizados na Ficha de Levantamento Hidrológico, e, na terceira etapa de campo, foram realizadas as coletas de dados que constam da ficha, em dois LIH do rio Selho localizados no Mapa 1, no Concelho de Guimarães, distrito de Braga, Portugal, para compor a metodologia para a avaliação e classificação de hidrossítios.

\section{Mapa 1 - Pontos de coleta de dados da Ficha de Levantamento Hidrológico no rio Selho, na Bacia Hidrográfica do Rio Selho, no município de Guimarães, ao norte de Portugal}

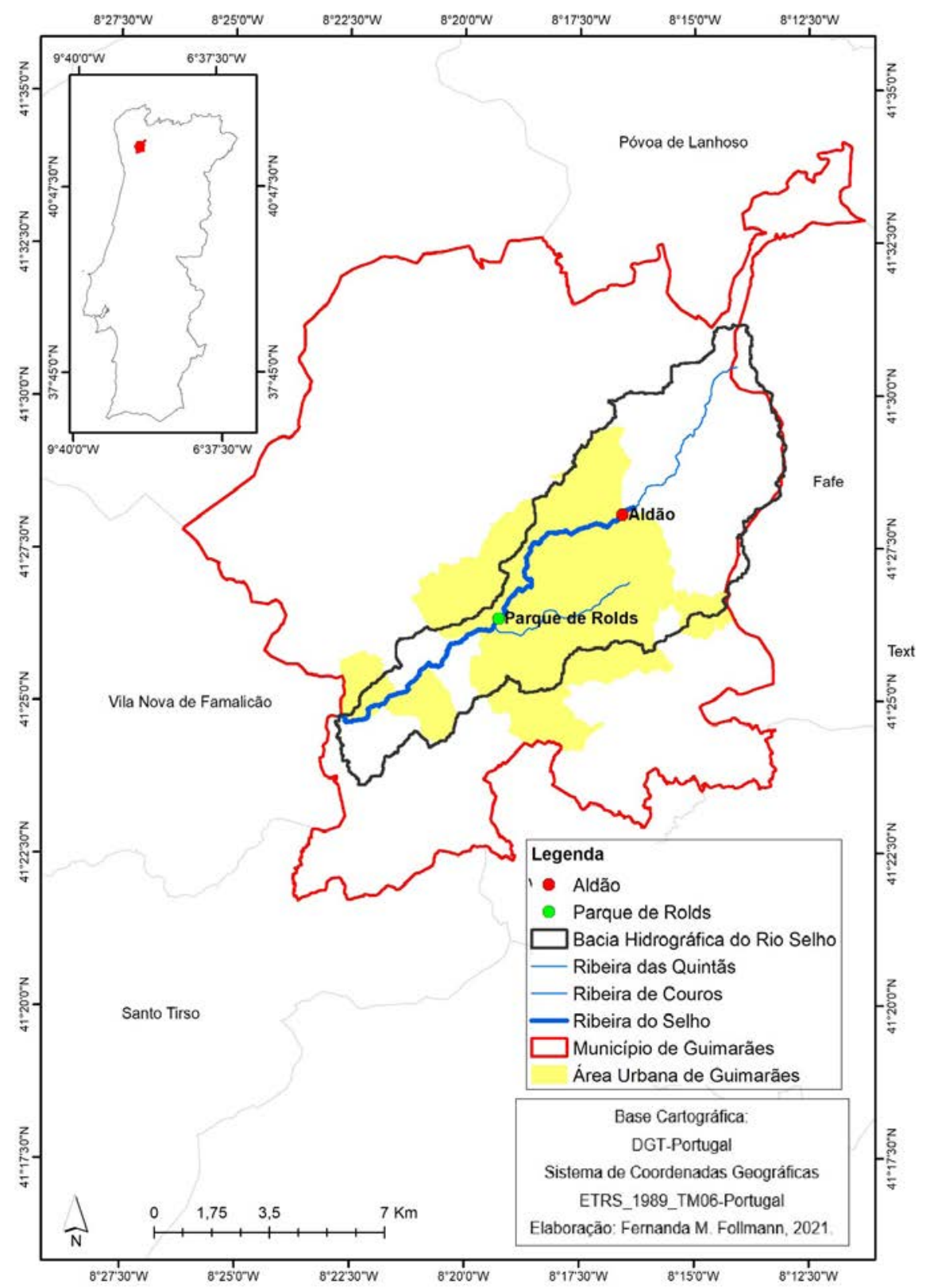




\section{Avaliação e classificação de hidrossítios no rio Selho: Parque de Roldes e Aldão}

Para validação da metodologia de avaliação e classificação de hidrossítios, inicialmente, foram selecionados $\mathrm{LIH}$ no rio Selho com potencial patrimonial, segundo critérios ecológico, estético, sociocultural e complementar por meio de imagens de satélite pelo software Google Earth e de dados do Projeto Rios-Prios, de requalificação do rio Selho, executado na Freguesia de Fermentões pela câmara municipal de Guimarães, em parceria com o Departamento de Geografia da Universidade do Minho (Costa, 2013).

Os LIH localizam-se no rio Selho, afluente da margem esquerda do rio Ave, que atravessa o perímetro urbano no Concelho de Guimarães, distrito de Braga, Portugal. As nascentes do rio Selho situam-se no Concelho de Fafe, com 18,9 km de comprimento do rio principal até - Concelho de Guimarães, atravessando a extremidade NE da freguesia de Gonça até o limite SW da freguesia de Gondar, limite do concelho na confluência com o rio Ave (Ribeiro; Correia; Costa, 2004, p. 3).

Pela localização geográfica na transição do perímetro urbano com o rural, as margens do rio foram sendo alteradas ao longo do tempo para usos urbano e agrícola, em que várias intervenções foram sendo executadas para o uso da água, alguns desses bens e equipamentos, porém, ainda permanecem como testemunho de um tempo espaço:

Ao longo do Rio Selho podem ainda encontrar-se diversas infra-estruturas que enriquecem ainda mais esse património, tais como moinhos, diques, fábricas e aproveitamentos hidroelétricos, que usando a energia hidráulica, apoiaram directamente as actividades humanas, das quais se salientam a moagem de farinhas, a laboração fabril e a produção de energia eléctrica (Ribeiro; Correia; Costa, 2004, p. 1).

As informações de localização, rotas de deslocamento, uso e cobertura da terra foram obtidas da imagem de satélite Google Earth, complementadas com as do Projeto Rios-Prios com objetivo de propor intervenções para a melhoria do ecossistema hídrico, uso racional e a proteção dos recursos hídrico (Costa, 2013), e ainda, com a Ficha de Levantamento Hidrológico no levantamento realizado em trabalhos de campo. Os dois segmentos selecionados para avaliação no rio Selho: Parque de Roldes (PR), da Ponte Românica a montante até o açude da Fábrica Couros, e o Segmento do Aldão (SA) da Ponte Românica do Aldão a montante até Moinho de Cereais, apresentam: qualidade da água, características hidromorfológicas, dinâmica e intervenções para uso no mesmo rio, localizados na transição de uso urbano e rural. A referência para a análise e interpretação hídrica foi o leito dos rios, a montante das Pontes Românica em aproximadamente $150 \mathrm{~m}$ e, o entorno a partir das margens afastando-se do rio $50 \mathrm{~m}$.

No segmento do Parque de Roldes (PR) (Figura 1), a análise visual permitiu concluir, quanto à boa qualidade da água, às alterações hidromorfológicas do canal, às margens e às construções de valor histórico ou cultural. Na foto 1 (Figura 1), tomada na horizontal da margem esquerda no sentido da montante, é possível observar a intervenção com barramento do fluxo da água, transpondo em pequena queda, com alteração do leito e da margem. Na foto 2 (Figura 1), na mesma posição da foto anterior, uma pequena ponte de acesso à fábrica, com interferência 
no fluxo hídrico do rio. Na foto 3 (Figura 1), da margem esquerda, alguns metros a jusante, com visada horizontal, direção frontal no segmento do leito com vista da margem direita com fragmentos de vegetação e intervenção no leito do rio. Na foto 4 (Figura 1)), no mesmo segmento do leito em direção a jusante, com acúmulo de sedimentos à direita do leito. Na foto 5 (Figura 1), ainda no mesmo sentido, fragmento arborizado na área do Parque, alteração da margem. Finalmente, na foto 6 (Figura 1), a Ponte Românica, de importância histórico-cultural, com obstrução do fluxo d'água gerado pela estrutura da ponte. No conjunto da paisagem, o corpo hídrico tem valor diferenciado, considerando o contexto do município de Guimarães. Posteriormente, apresentam-se os valores da avaliação de acordo com os critérios, indicadores e classes propostos na ficha.

\section{Figura 1 - Imagens do Parque de Roldes-PR}

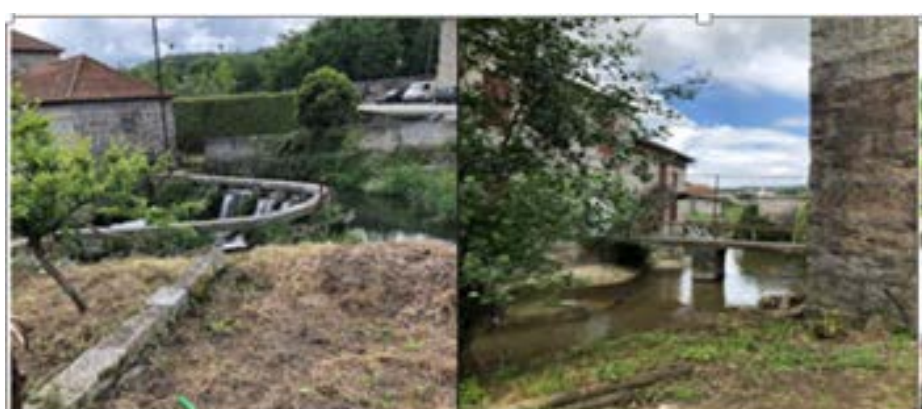

(1)

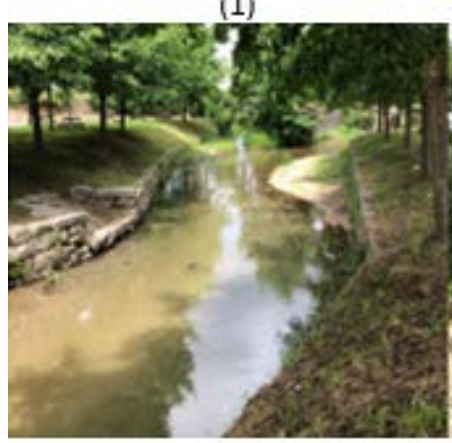

(4)
(2)

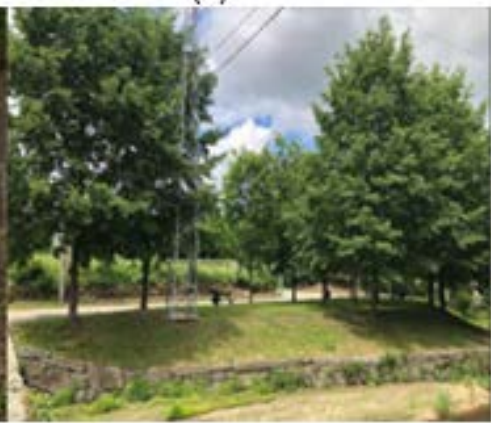

(5)

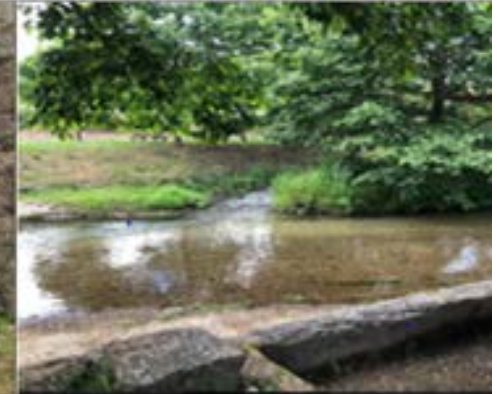

(3)

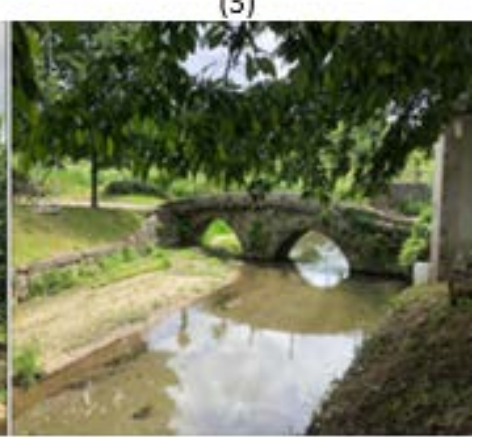

(6)

fonte: Trabalho de campo, Uminho, 29 maio 2020.

O segmento Aldão (Figura 2), fica a jusante do Parque de Roldes. Tomando como referência a Ponte do Aldão, a avaliação foi realizada da montante até o Moinho, com base na análise visual da água, das condições do leito e das margens, da qualidade visual e das intervenções antrópicas. Na foto 7 (Figura 2), tomada na horizontal, a montante da ponte do Aldão, na margem esquerda, há um pequeno barramento com acúmulo d’água e transponibilidade com queda de aproximadamente um metro. Na foto 8 (Figura 2), no mesmo ponto que a foto anterior, com tomada a jusante, o leito apresenta obstáculo e margem direita alterada. Na foto 9 (Figura 2), o fluxo com obstáculo na coluna de sustentação da ponte, leito alterado na margem esquerda, com fragmentos de vegetação nas margens. As fotos 10, 11 e 12 (Figura 2) foram tomadas na horizontal, margem esquerda na Ponte do Aldão. Nas fotos 10 e 11 (Figura 2), a dinâmica fluvial caracteriza-se como turbulenta, em virtude dos obstáculos naturais e artificiais no leito do rio, compondo cenário de contemplação e aproveitamento turístico regional, com construção de infraestrutura 
para alojamento. A Ponte Românica, de valor histórico-cultural, barra o fluxo da água, que perde capacidade de transporte de sedimentos, assoreando o leito do rio. Os dados da avaliação hidrológica desse ponto são apresentados a seguir (Figura 3).

\section{Figura 2 - Segmento Aldão, a jusante do Parque de Roldes}

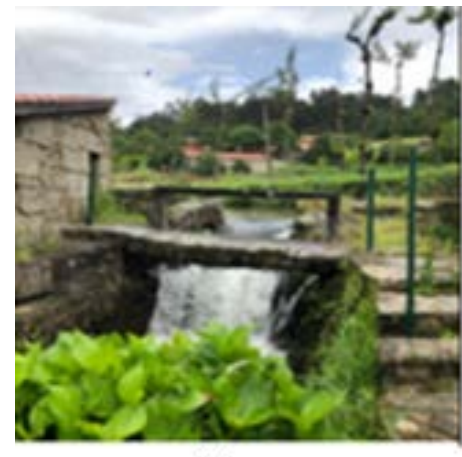

(7)

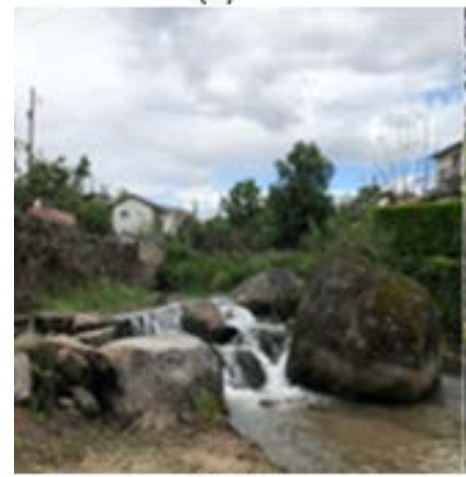

(10)

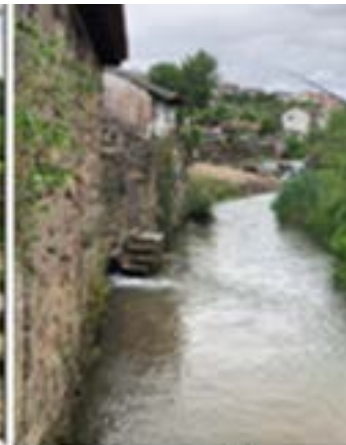

(8)

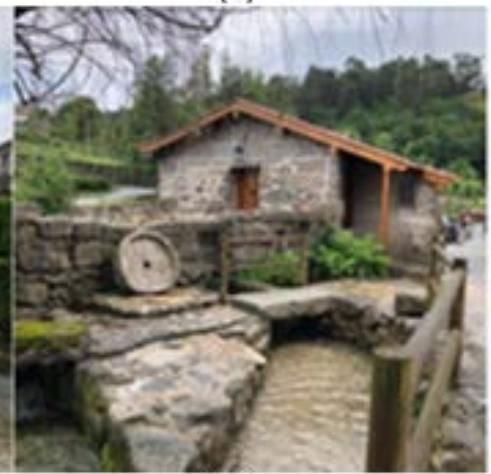

(11)

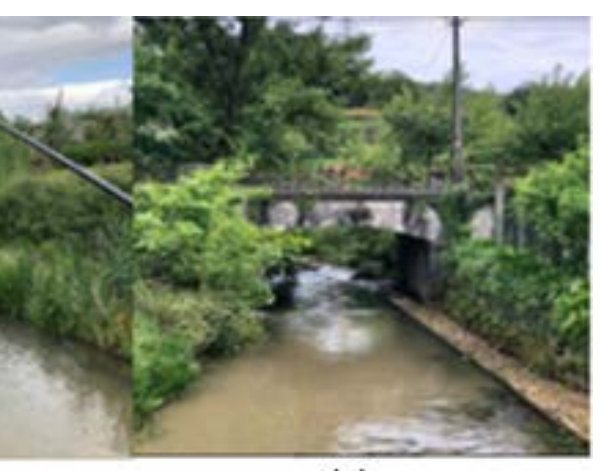

(9)

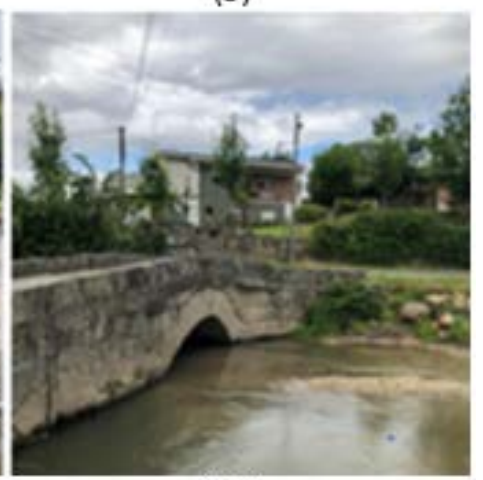

(12)

fonte: Trabalho de campo, Uminho, 29 maio 2020.

Os dados obtidos nos trabalhos de campo no segmento Parque de Roldes (PR) e no segmento Aldão (SA) são apresentados a seguir, na Ficha de Levantamento Hidrológico; os valores atribuídos foram ponderados de acordo com o valor percentual das classes dos indicadores e critérios, obtendo-se, assim, o valor do LIH para a classificação de acordo com o maior valor obtido.

\section{Figura 3 - Ficha de Levantamento Hidrológico}

\section{FICHA DE LEVANTAMENTO HIDROLÓGICO}

\section{Nome}

Localização:

Referência:

Corpo hídrico: ( ) nascente ( ) segmento rio ( ) lago: ( ) natural ( ) artificial ( ) aquífero

Regime fluxo dominante: ( ) laminar ( ) turbulento

\section{Fenômeno hídrico:}

( ) surgência ( ) queda d'água: cachoeira, cascata ( ) redemoinho ( ) sumidor Outros

\section{Intervenção para uso água:}

Barramento: ( ) abastecimento ( ) energia ( ) paisagismo lazer/recreação

Roda d'água: ( ) energia ( ) abastecimento

Outros: 


\begin{tabular}{|c|c|c|c|c|c|c|}
\hline \multicolumn{2}{|c|}{ CRITÉRIO ECOLÓGICO - INDICADORES } & \multirow{2}{*}{$\begin{array}{l}\text { CLASSES } \\
\text { Muito ruim }\end{array}$} & \multicolumn{2}{|c|}{ Valor 65\% } & \multirow{2}{*}{ PR } & \multirow[t]{2}{*}{ SA } \\
\hline \multirow{30}{*}{ QUALIDADE (40\%) } & \multirow{5}{*}{$\begin{array}{l}\mathrm{PH}-\mathrm{ACIDEZ} \text { ÁGUA } \\
(4 \%)\end{array}$} & & 0 & 0 & & \\
\hline & & Ruim & 1 & 1 & & \\
\hline & & Razoável & 2 & 2 & & \\
\hline & & Bom & 3 & 3 & & \\
\hline & & Excelente & 4 & 4 & $x$ & $x$ \\
\hline & \multirow{5}{*}{$\begin{array}{l}\text { OXGÊNIO DISSOLVIDO } \\
(4 \%)\end{array}$} & Muito ruim & 0 & 0 & & \\
\hline & & Ruim & 1 & 1 & $x$ & $x$ \\
\hline & & Razoável & 2 & 2 & & \\
\hline & & Bom & 3 & 3 & & \\
\hline & & Excelente & 4 & 4 & & \\
\hline & \multirow{5}{*}{$\begin{array}{l}\text { CONDUTIVIDADE } \\
(4 \%)\end{array}$} & Muito ruim & 0 & 0 & & \\
\hline & & Ruim & 1 & 1 & & \\
\hline & & Razoável & 2 & 2 & & \\
\hline & & Bom & 3 & 3 & & \\
\hline & & Excelente & 4 & 4 & $x$ & $x$ \\
\hline & \multirow{5}{*}{$\begin{array}{l}\text { ESTADO TRÓFICO DA } \\
\text { ÁGUA } \\
(10 \%)\end{array}$} & Alto acúmulo & 0 & 0 & & \\
\hline & & Muito acúmulo & 1 & 2,50 & & \\
\hline & & Médio & 2 & 5 & & \\
\hline & & Pouco acúmulo & 3 & 7,50 & $x$ & \\
\hline & & Sem acúmulo & 4 & 10 & & $x$ \\
\hline & \multirow{5}{*}{$\begin{array}{l}\text { BIODIVERSIDADE } \\
\text { AQUÁTICA } \\
(10 \%)\end{array}$} & Sem vida & 0 & 0 & & \\
\hline & & Poucas espécies & 1 & 2,50 & $x$ & $x$ \\
\hline & & Diversas espécies & 2 & 5 & & \\
\hline & & Muitas espécies & 3 & 7,50 & & \\
\hline & & Abundância espécies & 4 & 10 & & \\
\hline & \multirow{5}{*}{$\begin{array}{l}\text { COBERTURA DE } \\
\text { MARGENS } \\
(8 \%)\end{array}$} & Sem vegetação & 0 & 0 & & \\
\hline & & Forte alteração & 1 & 2 & & $x$ \\
\hline & & Fragmentada & 2 & 4 & $x$ & \\
\hline & & Leve alteração & 3 & 6 & & \\
\hline & & Natural & 4 & 8 & & \\
\hline \multirow{20}{*}{$\begin{array}{l}\text { CONDIÇÃO } \\
\text { HIDROMORFOLÓGICA } \\
(25 \%)\end{array}$} & \multirow{5}{*}{$\begin{array}{l}\text { TIPOLOGIA } \\
(2,5 \%)\end{array}$} & Barragem & 0 & 0 & & \\
\hline & & Enrocamento & 1 & 0,625 & $x$ & $x$ \\
\hline & & Soleira/lajeado & 2 & 1,25 & & \\
\hline & & Pequeno controle & 3 & 1,875 & & \\
\hline & & Sem obstáculo & 4 & 2,5 & & \\
\hline & \multirow{5}{*}{$\begin{array}{l}\text { TRANSPONIBILIDADE } \\
\text { ESCOAMENTO } \\
(7,5 \%)\end{array}$} & Albufeira/lago & 0 & 0 & & \\
\hline & & Regolfo/barramento & 1 & 1,875 & $x$ & $x$ \\
\hline & & Com queda d'água & 2 & 3,75 & & \\
\hline & & Sem queda d'água & 3 & 5,625 & & \\
\hline & & Sem interferência & 4 & 7,5 & & \\
\hline & \multirow{5}{*}{$\begin{array}{l}\text { BALANÇO EROSÃO/ } \\
\text { DEPOSIÇÃO } \\
(7,5 \%)\end{array}$} & Alterado & 0 & 0 & $x$ & $x$ \\
\hline & & Forte desequilibrio & 1 & 1,875 & & \\
\hline & & Desequilibrado & 2 & 3,75 & & \\
\hline & & Leve alteração & 3 & 5,625 & & \\
\hline & & Equilibrado & 4 & 7,5 & & \\
\hline & \multirow{5}{*}{$\begin{array}{l}\text { FORMA } \\
(7,5 \%)\end{array}$} & Sem expressão & 0 & 0 & $x$ & $x$ \\
\hline & & Pouco perceptível & 1 & 1,875 & & \\
\hline & & Expressiva & 2 & 3,75 & & \\
\hline & & Muito expressiva & 3 & 5,625 & & \\
\hline & & Dominante & 4 & 7,5 & & \\
\hline
\end{tabular}




\begin{tabular}{|c|c|c|c|c|c|c|}
\hline \multicolumn{2}{|c|}{ CRITÉRIO ESTÉTICO - INDICADORES } & \multirow{2}{*}{$\begin{array}{l}\text { CLASSES } \\
\text { Totalmente alterado } \\
\end{array}$} & \multicolumn{2}{|c|}{ Valor $10 \%$} & \\
\hline \multirow{10}{*}{$\begin{array}{l}\text { QUALIDADE } \\
\text { VISUAL } \\
(10 \%)\end{array}$} & \multirow{5}{*}{$\begin{array}{l}\text { CANAL } \\
(5 \%)\end{array}$} & & 0 & 0 & & $x$ \\
\hline & & Grande alteração & 1 & 1,25 & $x$ & \\
\hline & & Alterado & 2 & 2,5 & & \\
\hline & & Ligeiramente alterado & 3 & 3,75 & & \\
\hline & & Natural & 4 & 5 & & \\
\hline & \multirow{5}{*}{$\begin{array}{l}\text { COBERTURA TERRA } \\
(5 \%)\end{array}$} & Degradada & 0 & 0 & & \\
\hline & & Desqualificada & 1 & 1,25 & & $x$ \\
\hline & & $\begin{array}{l}\text { Leve alteração } \\
\text { Urbano }\end{array}$ & 2 & 2,5 & & \\
\hline & & Leve alteração rural & 3 & 3,75 & $x$ & \\
\hline & & Natural & 4 & 5 & & \\
\hline \multicolumn{2}{|c|}{$\begin{array}{l}\text { CRITÉRIO SOCIOCULTURAL - } \\
\text { INDICADORES }\end{array}$} & CLASSES & \multicolumn{2}{|c|}{ Valor $15 \%$} & & \\
\hline \multirow{10}{*}{$\begin{array}{l}\text { BENS E } \\
\text { EQUIPAMENTOS } \\
(15 \%)\end{array}$} & \multirow{5}{*}{$\begin{array}{l}\text { SIGNIFICADO } \\
\text { HISTÓRICO- } \\
\text { CULTURAL } \\
(7,5 \%)\end{array}$} & Sem relevância & 0 & 0 & & \\
\hline & & Pouca relevância & 1 & 1,875 & & $x$ \\
\hline & & Média relevância & 2 & 3,75 & & \\
\hline & & Importante & 3 & 5,625 & $x$ & \\
\hline & & Grande relevância & 4 & 7,5 & & \\
\hline & \multirow{5}{*}{$\begin{array}{l}\text { FUNÇÃO } \\
\text { NATURAL/SOCIAL } \\
(7,5)\end{array}$} & Econômica & 0 & 0 & $x$ & $x$ \\
\hline & & Histórico-cultural & 1 & 1,875 & & \\
\hline & & Geomorfologia fluvial & 2 & 3,75 & & \\
\hline & & Ecológica & 3 & 5,625 & & \\
\hline & & Ecossocial & 4 & 7,5 & & \\
\hline \multicolumn{2}{|c|}{$\begin{array}{l}\text { CRITÉRIO COMPLEMENTAR - } \\
\text { INDICADORES }\end{array}$} & CLASSES & \multicolumn{2}{|c|}{ Valor $10 \%$} & & \\
\hline \multirow{5}{*}{$\begin{array}{l}\text { CIENTÍFICO } \\
(2,5 \%)\end{array}$} & \multirow{5}{*}{$\begin{array}{l}\text { IMPORTÂNCIA } \\
\text { CIENTÍFICA } \\
(2,5 \%)\end{array}$} & Nenhuma & 0 & 0 & & $x$ \\
\hline & & Pouca & 1 & 0,625 & $x$ & \\
\hline & & Média & 2 & 1,25 & & \\
\hline & & Alta & 3 & 1,875 & & \\
\hline & & Elevada & 4 & 2,5 & & \\
\hline \multirow{5}{*}{$\begin{array}{l}\text { GESTÃO } \\
(5 \%)\end{array}$} & \multirow{5}{*}{$\begin{array}{l}\text { NORMAS PARA A } \\
\text { CONSERVAÇÃO } \\
(5 \%)\end{array}$} & Nenhuma & 0 & 0 & & \\
\hline & & Para outros fins & 1 & 1,25 & & \\
\hline & & Para o entorno & 2 & 2,5 & & \\
\hline & & Para a sub-bacia & 3 & 3,75 & $x$ & $x$ \\
\hline & & Específica para água & 4 & 5 & & \\
\hline \multirow{5}{*}{$\begin{array}{l}\text { GEOLÓGICO } \\
\text { GEOMORFOLÓGICO } \\
(2,5 \%)\end{array}$} & \multirow{5}{*}{$\begin{array}{l}\text { PROCESSOS } \\
\text { ESTRUTURAIS } \\
\text { ESCULTURAIS } \\
(2,5 \%)\end{array}$} & Nada representativo & 0 & 0 & $x$ & $x$ \\
\hline & & Pouco representativo & 1 & 0,625 & & \\
\hline & & Relativamente & 2 & 1,25 & & \\
\hline & & Representativo & 3 & 1,875 & & \\
\hline & & Muito representativo & 4 & 2,5 & & \\
\hline
\end{tabular}

fonte: Os autores.

Na avaliação dos LIH do rio Selho, os valores dos parâmetros físico-químicos da qualidade da água foram obtidos do Projeto de Inventariação e Avaliação Ambiental de Obstáculos no Rio Selho para a Decisão de Remoção e Valorização da Linha de Água, coordenado pelo Laboratório da Paisagem e Centro de Estudos de Comunicação e Sociedade da Universidade do Minho. 
Os demais dados foram levantados por análise visual em trabalho de campo usando a Ficha de Levantamento Hidrológico. Os dois segmentos apresentam características semelhantes quanto a propriedades físico-químicas, sendo que o OD foi classificado como ruim, o PH e a condutividade apresentam excelente resultado; o estado trófico, no PR, pouco acúmulo de sedimentos em suspensão e, no SA, sem acúmulo.

Por sua vez, a biodiversidade aquática caracteriza-se por pequeno número de espécies; a cobertura de uso da terra de margens, no PR, apresenta vegetação arbórea pouco desenvolvida apresenta uma mescla de espécies ribeirinhas e não ribeirinhas, fragmentada com características naturais, ora ocupada por uma galeria ripícola, ora com uma cobertura herbácea ou arbustiva, especialmente quando em presença de campos de cultivo agrícola. A vegetação ripícola que às vezes se encontra nesse local é constituída por amieiros e salgueiros que tendem a fixar-se nos muros, conforme Costa (2013), enquanto a condição de margem se caracteriza por forte alteração com ocupação de maior densidade e poucas espécies vegetais exóticas e de pequeno porte.

Entre os indicadores hidromorfológicos, ambos se caracterizam, quanto à tipologia, como enrocamento, causando represamento com acúmulo do fluxo da corrente; transponibilidade em regolfo, com alteração da dinâmica da corrente em alguns metros a montante; no balanço de erosão/deposição do canal, percebe-se forte desequilibrio, com deposição de sedimentos nas laterais do canal fluvial, demonstrando a perda na capacidade de transporte, pela redução da velocidade ou da quantidade do fluxo de água. As formas decorrentes da dinâmica fluvial sem expressão, pequenas quedas d'água geradas pelo enrocamento, o conjunto dos indicadores demonstra a forte alteração das condições hidromorfológicas por intervenções antrópicas no fluxo da corrente no leito do rio.

$\mathrm{Na}$ avaliação do valor estético definido pela qualidade visual do canal, em ambos os casos, apresenta-se bastante alterado, com margens do leito muradas; e a cobertura da terra no entorno, no segmento do PR, foi classificada como rural levemente alterado, favorecido pela execução do Prios, apresentando melhor qualidade visual de entorno, o SA apresenta cobertura da terra no seu entorno totalmente desqualificada com locais marcados pela degradação urbana.

A avaliação do critério sociocultural focando os bens e equipamentos de intervenção no fluxo da corrente para o aproveitamento da água apresenta significado histórico-cultural, no PR, avaliado como relativamente importante, considerando a história da indústria do couro em Guimarães, e, no SA, apresenta pouca relevância considerando os moinhos de grãos. Quanto à função dos usos dos recursos hídricos, em ambos, destina-se ao aproveitamento econômico como fonte de energia e paisagismo.

As estruturas físicas e as infraestruturas existentes nos LIH do rio Selho, como os canais ao longo das margens que desviam o fluxo da água para o aproveitamento da energia hidráulica para moagem de cereais, e no paisagismo de habitações de alojamento local, as Pontes Românicas de valor histórico nos dois locais têm pilares largos, capazes de provocar um efeito regressivo na velocidade das águas, com arcos relativamente pequenos comprometendo uma resposta rápida ao aumento da vazão, interferem na dinâmica fluvial como obstáculo à drenagem das águas e ao transporte de sedimentos, contribuindo com o assoreamento do leito e alterando o fluxo principal da água. 
Quanto aos critérios complementares, os LIH não apresentam destaque para pesquisas científicas, nenhuma característica hídrica rara ou excepcional quanto à qualidade, dinâmica, interferência no regime fluvial de interesse cientííco. $O$ destaque fica por conta da gestão, sendo que ambos se localizam no domínio da Reserva Ecológica Nacional, áreas relevantes para a sustentabilidade do ciclo hidrológico terrestre, contemplam os cursos de água e respectivos leitos e margens, são áreas com restrição de uso por serem de utilidade pública, equiparando-se as áreas de preservação permanente no Brasil.

Outro indicador remete à avaliação da interdependência hídrica com os processos e formas que são associados a geomorfologia fluvial, que, nesses locais, não apresentam nenhum destaque que possa ser valorado como excepcional ou raro.

Após a ponderação dos valores atribuídos em trabalho de campo, há que se considerar que, na perspectiva do geopatrimônio, a condição para um hidrossítio é ter elevado valor ecológico, estético, sociocultural e complementar, sendo que o LIH alcançara o status de hidrossítio se obtiver valoração superior a $50 \%$ do critério ecológico.

Propõe-se que, após a soma dos valores atribuídos, se o LIH obtiver de $0-49 \%$ do valor total, ele não deve ser designado como hidrossítio, se o valor obtido for entre $50-74 \%$ do valor total, o LIH tem potencial para hidrossítio e, para isso, devem-se encaminhar aos órgãos de gestão os indicadores a ser melhorados para a obtenção futura do status patrimonial; finalmente, se obtiver a pontuação de $75 \%$ do valor total, o LIH receberá o status de hidrossítio.

Após a soma dos valores obtidos em trabalhos de campo, a metodologia demonstra que os LIH no rio Selho: Parque de Roldes com 40,5\% e Aldão, 32,8\% do valor total, não têm valoração suficiente para ser considerados hidrossítios, pelas alterações na qualidade da água, condições hidromorfológicas, qualidade visual e intervenções para o uso da água, demandam ações do poder público para melhorar a condição como área da Reserva Ecológica Nacional.

Como resultado, a metodologia para a classificação de hidrossítios mostra-se válida, os resultados demonstram coerência entre aspectos teórico-metodológicos e a realidade do corpo hídrico no campo, assim, valida os critérios, indicadores e classes com seus respectivos índices percentuais. Enfim, a metodologia possibilita que se identifiquem e expressem resultados adequados à realidade dos elementos naturais e artificiais que configuram os LIH avaliados.

Concluindo constata-se que quanto maior o valor dos critérios ecológico, estético, socioculturais e complementares que compõem a paisagem da água do hidrossítio, maior será o potencial atrativo geoturístico.

As diferentes abordagens do geopatrimônio apontam a valorização de áreas que, embora não tenham grande expressão regional ou internacional, têm significado ecológico, estético, sociocultural ou complementar, merecem medidas de proteção e o reconhecimento de seu valor, a ser divulgado e trabalhado junto às comunidades e aos órgãos públicos.

\section{Considerações finais}

A proposta de avaliação e classificação dos LIH atende aos corpos hídricos superficiais e precisa ser adaptada às condições da geografia e dos instrumentos legais de cada país.

Devem-se fazer adequações quando o LIH avaliado não tiver intervenção antrópica para uso da água, caso típico de rios em unidades de conservação de proteção integral, retirando o 
critério sociocultural da avaliação e redistribuindo de forma equitativa entre os demais critérios os valores que the foram inicialmente atribuídos.

Quando houver intervenções antrópicas de barramento total, há que considerar a permeabilidade do fluxo e das espécies, a capacidade de superação do obstáculo afetando diretamente a biodiversidade aquática.

No critério sociocultural, um indicador a ser acrescentado, quando constatado, é o uso simbólico da água, por exemplo, em nascentes/afloramentos de grutas, os rios que são usados por várias religiões, afetando a relação da sociedade com a água.

A metodologia proposta demanda aprofundamento e qualificação de vários elementos, apresenta, como aspecto positivo, a contemplação de critérios, indicadores e classes com índices percentuais específicos de avaliação e classificação hidrológica, até então relegada ou indiretamente abordada nas discussões do geopatrimônio.

Ainda com a necessidade de replicação em diferentes contextos ambientais e de ocupação antrópica (com diferentes desenvolvimentos histórico-culturais) e a atribuição de valor cultural por populações/comunidades tradicionais, como nativos/indígenas, por exemplo, em que os processos de apropriação e percepção do território incidem diretamente no valor do conjunto de indicadores estéticos e socioculturais.

\section{Referências}

AGUILO ALONSO, M. et al. Guía para la elaboración de estudios del medio físico contenido y metodología. 5a reimp. Madrid: Ministerio de Medio Ambiente/ Secretaria de Estado para las Políticas del Agua y el Medio Ambiente, 2004.

AVILÉS, H. R. M.; ROMERO, T. R. El agua como patrimonio: educación y museos del agua. In: GÓMEZ ESPÍN, J. M.; HERVÁS AVILÉS, R. M. (Coord.). Patrimonio hidráulico y cultura del agua en el Mediterráneo. Murcia, ES: Fundación Séneca/Aecid, 2012. p. 13-32.

BRASIL. Ministério da Saúde. Fundação Nacional de Saúde. Manual de controle da qualidade da água para técnicos que trabalham em Etas. Brasília, DF: Funasa, 2014. Disponível em: http://www.funasa.gov.br/documents/20182/38937/ Manual+de+controle+da+qualidade $+\mathrm{da}+\% \mathrm{C} 3 \% \mathrm{Algua}+$ para $+\mathrm{t} \% \mathrm{C} 3 \% \mathrm{~A} 9 \mathrm{cnicos}+$ que+trabalham+em+ETAS+2014.pdf/85bbdcbc-8cd2-4157-940b-90b5c5bcfc87. Acesso em: 2 mar. 2021.

BRASIL. Ministério do Meio Ambiente. Resolução Conama n. 357, de 17 de março de 2005. Dispõe sobre a classificação dos corpos de água e diretrizes ambientais para o seu enquadramento. Diário Oficial da União, Brasília, DF, n. 053, p. 58-63, 2005. Disponível em: 2http://www2.mma.gov.br/port/conama/legiabre.cfm?codlegi=459. Acesso em: 12 fev. 2021.

BRILHA, J. Património geológico e geoconservação: a conservação da natureza na sua vertente geológica. Braga, PT: Palimage, 2005. 
$\mathrm{CECCHIN,} \mathrm{D.} \mathrm{N.} \mathrm{Integração} \mathrm{do} \mathrm{patrimônio} \mathrm{cultural} \mathrm{ao} \mathrm{natural} \mathrm{como} \mathrm{recurso}$ geoturístico na implantação do projeto do geoparque Quarta Colônia,

RS, BR. Tese (Doutorado em Geografia) - Universidade Federal de Santa Maria, Santa Maria, 2019.

COSTA, F. S. Prios - Projecto de Reabilitação do Rio Selho: um exemplo de intervenção na zona urbana de Guimarães. In: Il CONGRESO INTERNACIONAL DE INGENIERÍA CIVIL Y TERRITORIO, 2., 2013, Vigo. Actas... Vigo, ES, 2013. p. 495-506.

ESTEVES, F. A. Fundamentos de Limnologia. 3a ed. Rio de Janeiro: Interciência, 1998.

FERREIRA, M. T.; AGUIAR, F. C. Riparian and aquatic vegetation in Mediterranean-type streams (western Iberia). Limnetica, n. 25, p. 411-424, 2006. doi: https://doi.org/10.23818/ limn.25.29.

GWP. GLOBAL WATER PARTNERSHIP. Catalyzing Change: A handbook for developing IWRM and water efficiency strategies. Stockholm, SE: GWP, 2004.

HERVÁS, F. N.; SERRANO, M. T. Factores de localización del patrimonio asociado al agua en el territorio de la Región de Murcia. In: GÓMEZ ESPÍN, J. M.; HERVÁS AVILÉS, R. M. (Coord.). Patrimonio hidráulico y cultura del agua en el Mediterráneo. Murcia, ES: Fundación Séneca/Aecid, 2012. p. 33-50.

MATA OLMO, R.; FERNÁNDEZ MUÑOZ, S. Paisajes y patrimonios culturales del agua: la salvaguarda del valor patrimonial de los regadíos tradicionales. Scripta NovaRevista Electrónica de Geografía y Ciencias Sociales, Barcelona: Universidad de Barcelona, v. 14, n. 337, 2010. Disponível em: http://www.ub.edu/geocrit/sn/sn-337. htm. Acesso em: 2 mar. 2021.

MEDEIROS, C. F. R. A utilização do River Habitat Survey como ferramenta de apoio à decisão na gestão dos recursos hídricos nos Açores. Dissertação (Mestrado em Engenharia do Ambiente) - Departamento de Geociências, Universidade dos Açores, Ponta Delgada, 2011.

MENDES, A. R. C. Avaliação da qualidade cênica da paisagem: aplicação da metodologia de Steinitz ao litoral alentejano. Dissertação (Mestrado em Arquictetura Paisagista) Instituto Superior de Agronomia, Universidade Técnica de Lisboa, Lisboa, 2010.

MONTEIRO, J. P. Da qualidade ecológica de zonas ripícolas e habitats fluviais no rio Paiva. Dissertação (Mestrado em Ecologia, Ambiente e Território) - Faculdade de Ciências, Universidade do Porto, Porto, 2013.

OLIVEIRA, K. A.; PESSOA, G. E.; STEINKE V. A. A estação ecológica de águas emendadas do Distrito Federal: patrimônio hidrogeomorfológico do Planalto Central do Brasil. In: ENCONTRO LUSO-BRASILEIRO DE PATRIMÓNIO GEOMORFOLÓGICO E GEOCONSERVAÇÃO, 3., 2019, Guimarães. Actas... Guimarães: Cegot/UMinho, 2019, p. 28-45.

PARLAMENTO EUROPEU. Diretiva 2000/60/CE do Parlamento Europeu e do Concelho. Estabelece um quadro de ação comunitária no domínio da política da 
água. Jornal Oficial das Comunidades Europeias, v. 43, L 327, 1-72, 23 dez. 2000. Disponível em: https://eur-lex.europa.eu/legal-content/PT/TXT/ PDF/?uri=OJ:L:2000:327:FULLEfrom=PT. Acesso em: 26 maio 2020.

PEREIRA, L. S.; CUNHA, L. S.; THEODORO, J. Um olhar sobre o patrimônio hidrológico do município de João Pessoa, Paraba, Nordeste do Brasil. In: NUNES, A.; MOREIRA, C. O.; PAIVA, I. R.; CUNHA, L. S. (Org.). Territórios de água = water territories. Coimbra, PT: Fluc/Cegot, 2016. p. 293-304.

PEREIRA, L. S.; CUNHA, L. S.; VIEIRA, R. S. Inventariação de potenciais locais de interesse geoturístico em João Pessoa (PB) e litoral sul do estado. Caminhos de Geografia, Uberlândia, v. 17, n. 60, p. 211-223, 2016. Disponível em: http://www.seer.ufu.br/index.php/ caminhosdegeografia/article/view/33653/19461. Acesso em: 2 mar. 2020.

PEYRET, P. Vias de água, paisagens: a noção de património fluvial. In: PEIXOTO, P.; CARDIELOS, J. P. A água como património: experiências de requalificação das cidades com água e das paisagens fluviais. Coimbra, PT: Imprensa da Universidade de Coimbra, 2016. p. 49-56.

PIO, S.; HENRIQUES, A. G. O estado ecológico como critério para a gestão sustentável das águas de superfície. In: CONGRESSO DA ÁGUA - A água e o desenvolvimento sustentável: desafios para o novo século, 5., 25-29 set. 2000, Lisboa. Actas... Lisboa: APRH, 2000. Disponível em: https://www.apambiente.pt/dqa/assets/estado-ecol\% C3\%B3gico-como-crit\%C3\%A9rio-para-a-gest\%C3\%A3o-sustent\%C3\%Alvel-das\%C3\%Alguas-de-superf\%C3\%ADcie.pdf. Acesso em: 2 mar. 2020.

PORTUGAL. Ministério do Ambiente do Ordenamento do Território e do Desenvolvimento Regional. Critérios para a classificação do estado das massas de água superficiais: rios e albufeiras. Lisboa: Instituto da Água IP, 2009. Disponível em: https:// www.apambiente.pt/dqa/assets/crit\%c3\%a9rios-classifica\%c3\%a7\%c3\%a3o-rios-ealbufeiras.pdf. Acesso em: 2 mar. 2020.

RAMOS-MERCHANTE, A.; PRENDA, J. Calidad del agua: herramientas para la determinación del estado ecológico de las masas de agua superficiales. In: GARCÍA, I. M. La gestión integrada de los recursos hídricos en Andalucía y norte de Marruecos. Sevilla, ES: Centa, 2015. p. 217-218.

RIBEIRO, A. C. C.; CORREIA, A. J. M.; COSTA, F. S. O rio Selho: contributo para uma proposta de requalificação ambiental. In: CONGRESSO NACIONAL DA GEOGRAFIA PORTUGUESA - Territórios e Protagonistas, 5., 2004, Guimarães. Actas... Guimarães, PT, 2004. p. 14 -16.

RODRIGUES, M. L. Património geomorfológico e geoturismo em áreas cársicas. In: III ENCONTRO LUSO-BRASILEIRO DE PATRIMÓNIO GEOMORFOLÓGICO E GEOCONSERVAÇÃO - A geoconservação no contexto do Antropoceno: desafios e oportunidades, 3., 2019, Guimarães: Cegot/Uminho. Actas... Coimbra, PT, 2019. 
RODRIGUES, M. L.; FONSECA, A. A valorização do geopatrimônio no desenvolvimento sustentável de áreas rurais. In: COLÓQUIO IBÉRICO DE ESTUDOS RURAIS Cultura, Inovação e Território, 7., 23-25 out. 2008, Coimbra. Actas... Coimbra, PT, 2008. Disponível em: http://www.sper.pt/oldsite/actas7cier/PFD/Tema\%20II/2_14.pdf. Acesso em: 28 mar. 2020.

SCIFONI, S. Os diferentes significados do patrimônio natural. Diálogos, Maringá, PR: UEM, v. 10, n. 3, p. 55-78, 2006

SELBORNE, L. A ética do uso da água doce: um levantamento. Brasilia, DF: Unesco, 2001. SIMIĆ, S.; GAVRILOVIĆ, L.; BELIJ, S. Hydrological heritage: new direction in hydrology and geoheritage. Glasnik Srpskog Geografskog Drustva, v. 90, n. 4, p. 83-102, 2010. doi: https://doi.org/10.2298/GSGD1004083S.

SIMIĆ, S.; MILOVANOVIĆ, B.; JOJIĆ GLAVONJIĆ, T. Theoretical model for the identification of hydrological heritage sites. Carpathian Journal of Earth Environmental Sciences, v. 9, n. 4, p. 19-30, 2014.

STEVAUX, J. C.; LATRUBESSE, E. M. Geomorfologia fluvial. São Paulo: Oficina de Textos, 2017. (Coleção Geografia, 3.)

TUCCI, C. E. M. (Org.). Hidrologia: ciência e aplicação. Porto Alegre: Ed. UFRGS, 2010.

TUNDISI, J. G.; MATSUMURA-TUNDISI, T. A água. São Carlos, SP: Scienza, 2020.

VIEIRA, A.; FIGUEIRÓ, A. S.; CUNHA, L. Metodologia de avaliação do património geomorfológico: aplicação à Serra de Montemuro (Portugal). In: ENCONTRO LUSO-BRASILEIRO DE PATRIMÓNIO GEOMORFOLÓGICO E GEOCONSERVAÇÃO, 1., 2014, Coimbra, PT: Universidade de Coimbra. Actas... Coimbra, PT, 2014. v. 1. p. 181-187.

\section{Contribuição dos autores:}

Eliane Maria Foleto: estruturação, discussão e elaboração do artigo, fundamentação do geopatrimônio, trabalhos de campo para propor critérios e indicadores para avaliação de locais de interesse hidrológico $(\mathrm{LIH})$, formulação de critérios e indicadores, definição de LIH da Ficha de Levantamento Hidrológico, trabalho de campo para a obtenção de dados da Ficha de Avaliação no rio Selho, redação e revisão do texto final do artigo.

Francisco Silva Costa: estruturação, discussão e elaboração do artigo, fundamentação do patrimônio hidráulico, trabalhos de campo, alteração dos parâmetros do critério ambiental ao proposto pela Diretiva do Quadro da Água e pela metodologia do River Habitat Survey, proposta das classes e dos valores percentuais dos indicadores, inserção de dados do Projeto 
Rios-Prios, de requalificação do rio Selho, e do Projeto Inventariação e Avaliação Ambiental de obstáculos no Rio Selho, coordenado pelo Laboratório da Paisagem e Centro de Estudos de Comunicação e Sociedade da Universidade do Minho, e revisão final e aprovação do artigo como supervisor do estágio de pós-doutorado.

Recebido em: 20 jul. 2020 Aprovado em: 19 fev. 2021 